\title{
Increased Production of Nitric Oxide Contributes to Renal Oxidative Stress in Endotoxemic Rat
}

\author{
${ }^{1}$ Bahar Tunçtan, ${ }^{1}$ Belma Korkmaz, ${ }^{2}$ Hatice Yıldırım, ${ }^{2}$ Lülüfer Tamer \\ ${ }^{2}$ Uğur Atik and ${ }^{1}$ C. Kemal Buharalıoğlu \\ ${ }^{1}$ Department of Pharmacology, Faculty of Pharmacy, Mersin University, Mersin, Turkey \\ ${ }^{2}$ Department of Biochemistry, Faculty of Medicine, Mersin University, Mersin, Turkey
}

\begin{abstract}
Overproduction of reactive oxygen and nitrogen species leads to oxidative stress and decreased total antioxidant capacity, which is responsible for high mortality from several diseases such as endotoxic shock. Nitric oxide (NO) produced by inducible NO synthase (iNOS) during endotoxemia is the major cause of vascular hyporeactivity, hypotension and multiple organ failure. In this study, we investigated whether increased production of NO contributes to renal oxidative stress in endotoxemic rat. Saline (4 mL kg${ }^{-1}$, i.p.), endotoxin (Escherichia coli lipopolysaccharide, O111:B4; $10 \mathrm{mg} \mathrm{kg}^{-1}$, i.p.) and/or selective iNOS inhibitor (1,3-PBIT; $10 \mathrm{mg} \mathrm{kg}^{-1}$, i.p.) were administered to conscious male Wistar rats and mean arterial blood pressure was recorded at 1, 2, 3 and $4 \mathrm{hr}$ after injection. Nitrite and malondialdehyde (MDA) levels and myeloperoxidase (MPO) activity were measured in the sera and/or kidney homogenates at the end of the experiments. Administration of endotoxin caused hypotension associated with increased systemic and renal nitrite production. 1,3-PBIT prevented these effects of endotoxin at $1 \mathrm{hr}$ after injection of endotoxin. Renal MPO activity was decreased by endotoxin which was not changed by 1,3-PBIT. Endotoxin caused a decrease in MDA levels in the renal tissue, which was prevented by 1,3-PBIT. These data suggest that overproduction of NO by iNOS during endotoxemia decreases renal oxidative stress and that inhibition of iNOS restores total renal antioxidant capacity.
\end{abstract}

Key words: Rat, kidney, endotoxin, inducible nitric oxide synthase, oxidative stress

\section{INTRODUCTION}

Oxidative stress results from an oxidant/antioxidant imbalance, an excess of oxidants and/or a depletion of antioxidants. The excessive production of reactive oxygen and nitrogen species (ROS and RNS, respectively) associated with inflammation leads to oxidative stress, which is involved with the high mortality from several diseases such as endotoxic shock $^{[1-4]}$. There is a considerable body of evidence for redox imbalance and oxidative stress in endotoxic shock. It has been reported that endotoxemia increases markers of oxidative stress and tissue injury in different animal models and in humans. This effect of endotoxin has been found to be correlated with decreased total antioxidant capacity and blood levels of several antioxidants such as $\alpha$-tocopherol, retinol, vitamin E, vitamin $C$ and $\beta$-carotene in humans with sepsis and septic shock ${ }^{[1-4]}$. It has also been reported that although total antioxidant capacity was decreased in patients with sepsis, it was increased in patients with septic shock $^{[5]}$. Increased xanthine oxidase, superoxide dismutase and glutathione peroxidase activity has also been reported in patients with sepsis suggesting increased production of $\operatorname{ROS}^{[6]}$.
However, malondialdehyde (MDA) (an index for lipid peroxidation) levels were also increased, suggesting that the elevations of these antioxidant enzymes were not so effective as to prevent cellular damage.

Among RNS, nitric oxide (NO) derived from inducible NO synthase (iNOS) is considered to be the major cause for systemic hypotension, vascular hyporeactivity, multiple organ failure and high mortality rate which is associated with septic shock ${ }^{[4-7]}$. Although the role of NO is controversial in tissue injury with oxidative DNA damage in endotoxemia, most of the clinical trials demonstrate that iNOS inhibitors may serve as a potentially effective pharmacological agents in alleviating endotoxin-induced decrease in antioxidant capacity and tissue injuries ${ }^{[1,4,7]}$. Since impairment of renal function during endotoxemia also contributes to multiple organ failure ${ }^{[2]}$, we investigated whether increased production of $\mathrm{NO}$ contributes to renal oxidative stress in endotoxemic rat.

\section{MATERIALS AND METHODS}

Chemicals: Endotoxin (lipopolysaccharide, Escherichia coli O111:B4), phenylene-1,3-bis[ethane2-isothiourea] dihydrobromide (1,3-PBIT), sodium 
nitrite, bovine serum albumin (BSA) and Bradford reagent were purchased from Sigma Chemical Co. (St. Louis, U.S.A.). Other chemicals were obtained from Merck (Darmstadt, Germany). All drugs were prepared daily in distilled water or saline.

Animals and endotoxic shock model: Male Wistar rats weighing 250 to $350 \mathrm{~g}$ were fed with standard chow. They were synchronised by maintenance of controlled environmental conditions throughout the duration of the experiments. The circadian rhythmicity of the animals was entrained by a standardised $12 \mathrm{~h}$ light and $12 \mathrm{~h}$ dark. All animal experiments were carried out according to the proposal of the U.S. National Institutes of Health Guide for the Care and Use of Laboratory Animals. The protocol was approved by ethics committee of Mersin University School of Medicine. Conscious rats received either endotoxin (10 $\mathrm{mg} \mathrm{kg}^{-1}$, i.p., sublethal dose) or saline $\left(4 \mathrm{~mL} \mathrm{~kg}^{-1}\right.$, i.p.) at time 0 and mean arterial blood pressure (MAP) was measured using the tail-cuff method at $0,1,2,3$ and 4 hr. Separate groups of rats were treated with endotoxin alone or in combination with the highly selective iNOS inhibitor 1,3-PBIT (10 $\mathrm{mg} \mathrm{kg}^{-1}$, i.p.) at $1 \mathrm{hr}$ after injection of saline or endotoxin. Rats were sacrificed 4 $\mathrm{hr}$ after endotoxin challenge and the blood and kidney were collected. Sera were obtained from blood samples by centrifugation at $18.000 \mathrm{rpm}$ for $15 \mathrm{~min}$ at $4^{\circ} \mathrm{C}$ and stored at $-20^{\circ} \mathrm{C}$ until analyzed for the measurement of nitrite levels. The tissues were homogenized in ice-cold buffer (1 mL) (mM: HEPES 20 [pH 7.5], $\beta$ glycerophosphate 20, sodium pyrophosphate 20 , sodium orthovanadate 0.2, EDTA 2, sodium fluoride 20 , benzamidine 10 , dithiothreitol 1 , leupeptin 20 and aprotinin 10 $)^{[8]}$. Cell debris was removed by centrifugation $18.000 \mathrm{rpm}$ for $15 \mathrm{~min}$ at $4^{\circ} \mathrm{C}$ followed by sonication for $15 \mathrm{sec}$ on ice with $50 \mu \mathrm{L}$ ice-cold Tris (50 mM, pH 8.0) and $\mathrm{KCl}(0.5 \mathrm{M})$. The samples were centrifuged at $18.000 \mathrm{rpm}$ for $15 \mathrm{~min}$ at $4^{\circ} \mathrm{C}$ and then supernatants were removed and stored at $-20^{\circ} \mathrm{C}$ until analyzed for the measurement of myeloperoxidase (MPO) activity and protein, nitrite and MDA levels.

Measurement of renal protein content: The protein content in the tissue homogenates was determined according to Coomassie blue method using BSA for standard $^{[9]}$. Briefly, Bradford reagent $(200 \mu \mathrm{L})$ were added to the mixture of tissue homogenate $(5 \mu \mathrm{L})$ and distilled water $(795 \mu \mathrm{L})$. Samples $(100 \mu \mathrm{L})$ were then pipetted into 96 well microtiter plates and absorbance was measured at $620 \mathrm{~nm}$ with a microplate reader (Organo Teknika Microwell System, Holland). Linear regression analysis was used to calculate the protein amount in the tissue homogenates from the standard calibration curves of BSA.
Measurement of serum and renal nitrite levels: In biological systems conversion of $\mathrm{NO}$ in aqueous solution to nitrite and nitrate is thought to favour nitrite production $^{[10]}$. It has been reported that nitrite is the only stable end-product of the autooxidation of NO in aqueous solution ${ }^{[11]}$ and measurement of nitrite concentrations in the serum and tissue homogenates widely accepted as an index for NOS activity ${ }^{[7,12-14]}$. Therefore, concentrations of nitrite in serum and tissue homogenates were measured by using the diazotization method based on the Griess reaction, which is an indirect assay for NO production ${ }^{[12]}$. Briefly, samples $(50 \mu \mathrm{L})$ were pipetted into 96 well microtiter plates and an equal volume of Griess reagent (1\% sulphanylamide $(25 \mu \mathrm{L})$ and $0.1 \% \quad \mathrm{~N}$-1-naphtylethylenediamine dihydrochloride $(25 \mu \mathrm{L})$ in $2.5 \%$ ortophosphoric acid) was added to each well. After incubation for $10 \mathrm{~min}$ at room temperature, absorbance was measured at $540 \mathrm{~nm}$ with a microplate reader (Organo Teknika Microwell System, Holland). Linear regression analysis was used to calculate the nitrite concentrations in the sera and the tissue homogenates from the standard calibration curves of sodium nitrite. Serum and tissue nitrite levels were expressed as $\mu \mathrm{M}$ or mmol mg protein ${ }^{-1}$, respectively.

Measurement of renal MPO activity: MPO is a haem-containing enzyme within the azurophil granules of neutrophils and MPO activity was measured as a simple quantitative method of detecting leukosequestration. The determination of MPO activity as an index of neutrophil infiltration in tissue homogenates depends on the fact that oxidized hidrogen peroxide reduces o-dianisidine ${ }^{[15]}$. Reduced odianisidine was measured at $410 \mathrm{~nm}$ by spectrophotometer. One unit of MPO activity was defined as that degrading $1 \mu \mathrm{mol}$ of hydrogen peroxide to water per minute at $25^{\circ} \mathrm{C}$. Tissue MPO activity was expressed as $\mathrm{U} \mathrm{mg}$ protein $^{-1}$.

Measurement of renal MDA levels: As an index of lipid peroxidation, the levels of MDA in tissue homogenates were determined by thiobarbituric acid reaction according to $\mathrm{Yagi}^{[16]}$. The method depends on the measurement of the pink color produced by interaction of the barbituric acid with MDA caused by lipid peroxidation. Linear regression analysis was used to calculate the MDA levels in the tissue homogenates from the standard calibration curves of 1,1,3,3tetraethoxypropane. Tissue MDA levels were expressed as mmol mg protein ${ }^{-1}$.

Statistical analysis: All data were expressed as means \pm SEM. Data were analyzed by one-way ANOVA followed by Student-Newman-Keuls test for multiple comparisons and unpaired Student's t or Mann-Whitney $\mathrm{U}$ tests when necessary. $P$ value of $<0.05$ was considered to be statistically significant. 


\section{RESULTS}

Endotoxin-induced fall in MAP is mediated by NO produced by iNOS: Injection of endotoxin caused a fall in MAP reaching from $134 \pm 4 \mathrm{mmHg}(\mathrm{n}=8)$ at 0 time to $109 \pm 5 \mathrm{mmHg}(\mathrm{n}=6)$ at $4 \mathrm{hr} \quad(P<0.05)$. Endotoxin-induced decrease in MAP was blunted by the administration of 1,3-PBIT $(129 \pm 7 \mathrm{mmHg}, \mathrm{n}=5)$ $(P<0.05)$. 1,3-PBIT alone had no effect on MAP $(146 \pm 3 \mathrm{mmHg}, \mathrm{n}=6) \quad(P>0.05)$. Endotoxin also increased systemic (Fig. 1A) and renal (Fig. 1B) nitrite production which were prevented by 1,3-PBIT $(P<0.05)$. 1,3-PBIT alone did not change the basal serum (Fig. 1A) and renal (Fig. 1B) nitrite levels $(P>0.05)$.

Endotoxin decreases renal MPO activity: To investigate the effect of endotoxin on neutrophil infiltration as an index for the development of inflammation, MPO activity was measured in the kidney from endotoxemic animals. Endotoxemia caused a decreased renal MPO activity which was not changed with 1,3-PBIT (Fig. 2). 1,3-PBIT alone had no effect on the basal MPO activity in the tissues (Fig. 2).

Endotoxin-induced increase in systemic and renal nitrite levels is associated with decreased oxidative stress: To investigate the effect of endotoxin on oxidative stress, one of the products of lipid peroxidation, MDA, was measured in the kidney from endotoxemic animals. Endotoxin decreased renal MDA levels (Fig. 3), which was prevented by 1,3-PBIT. 1,3PBIT alone had no effect on the basal MDA levels in the tissues (Fig. 3).

\section{DISCUSSION}

This study demonstrates that increased systemic NO production by iNOS $4 \mathrm{hr}$ after endotoxin injection causes hypotension in conscious rats and NO-derived from renal tissue also contributes to these effects of endotoxin. More importantly, we showed that endotoxemia-induced increase in NO production suppresses lipid peroxidation in the renal tissue and selective inhibition of iNOS with 1,3-PBIT restores renal antioxidant capacity presumably due to decreased levels of antioxidant molecules or activities of antioxidant enzyme systems.

Expression of iNOS protein and mRNA expression approximately $3 \mathrm{hr}$ after systemic endotoxin administration to animals has been reported in several tissues, such as blood vessels, heart, kidney and lung associated with significant increase in serum/plasma and tissue nitrite levels and decrease in $\mathrm{MAP}^{[7,17-19]}$. In our previous studies with conscious male SpragueDawley rats ${ }^{[8,20]}$, endotoxin $\left(10 \mathrm{mg} \mathrm{kg}^{-1}\right.$, i.p. $)$ causes a gradual fall in MAP during $4 \mathrm{hr}$ associated with renal iNOS protein expression as well as increased levels of
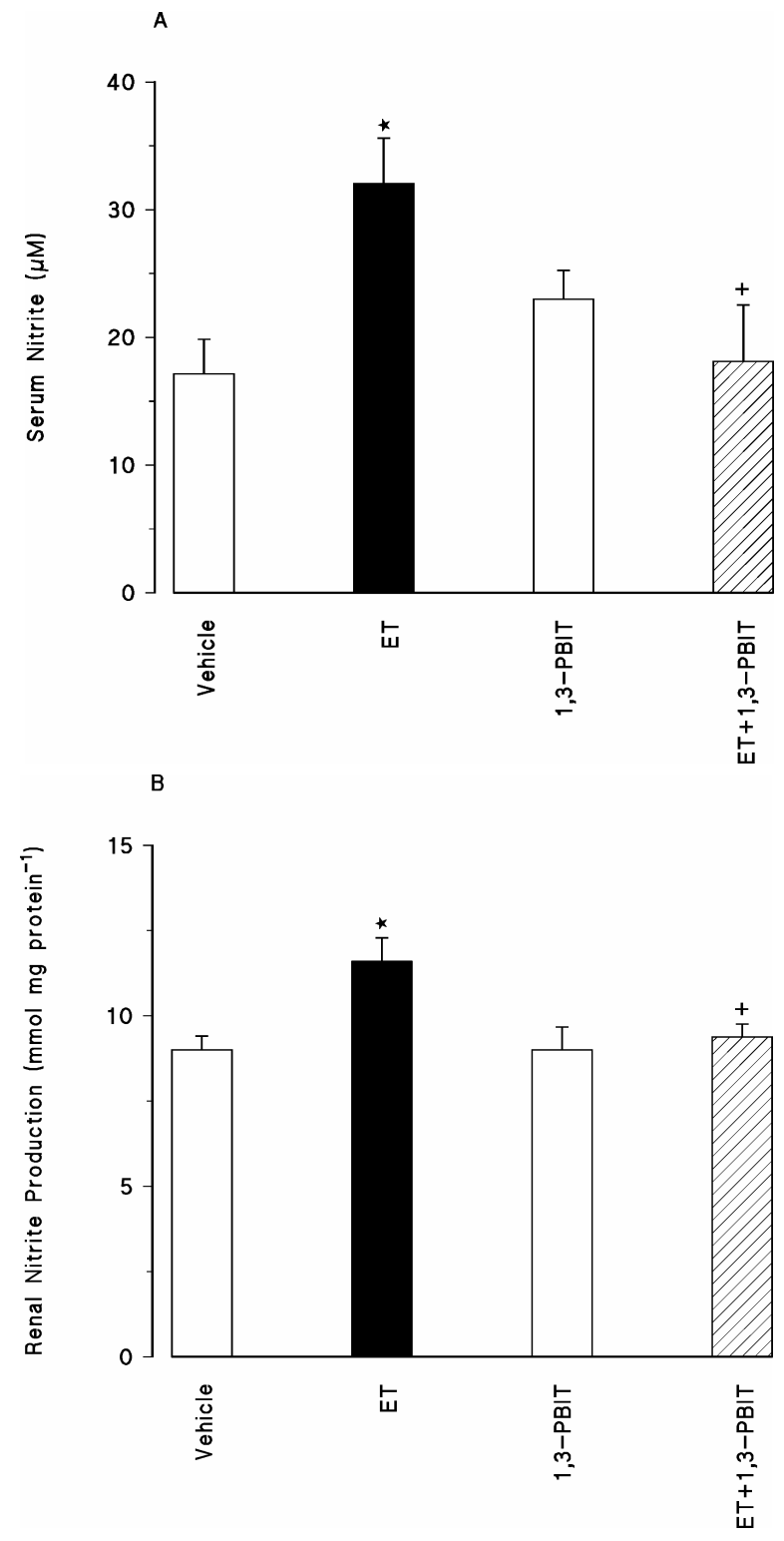

Fig 1: Effect of iNOS inhibition by 1,3-PBIT on changes in serum (A) and renal (B) nitrite levels $4 \mathrm{hr}$ after saline or endotoxin (ET) injection in conscious rats. Values are expressed as means \pm SEM from 4-10 rats per treatment group. ${ }^{*} P<0.05$ vs. saline-treated group (vehicle). ${ }^{+} P<0.05$ vs. ET-treated group.

nitrite in serum and kidney which are prevented by 1,3PBIT (10 mg kg-1, i.p.; $1 \mathrm{hr}$ after endotoxin). In the present study, administration of endotoxin to Wistar rats also decreased MAP at $4 \mathrm{hr}$ which was associated with an increase in the serum nitrite levels that was prevented after inhibition of iNOS with 1,3-PBIT. Endotoxin-induced increase in the renal nitrite production was also blunted by 1,3-PBIT. These observations suggest that NO produced by activation of iNOS in renal tissue contributes to the endotoxininduced hypotension in conscious rats. 


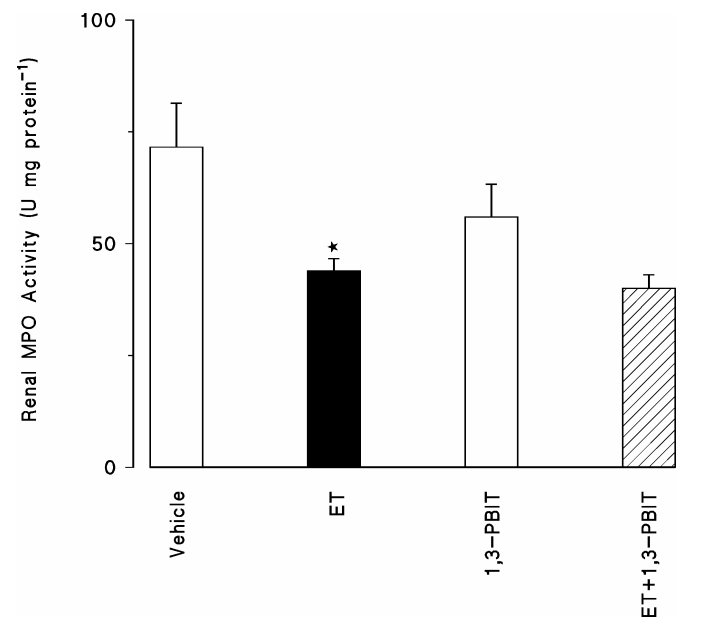

Fig. 2: Effect of iNOS inhibition by 1,3-PBIT on changes in renal myeloperoxidase (MPO) activity $4 \mathrm{hr}$ after saline or endotoxin (ET) injection in conscious rats. Values are expressed as means \pm SEM from 4-10 rats per treatment group. ${ }^{*} P<0.05$ vs. saline-treated group (vehicle).

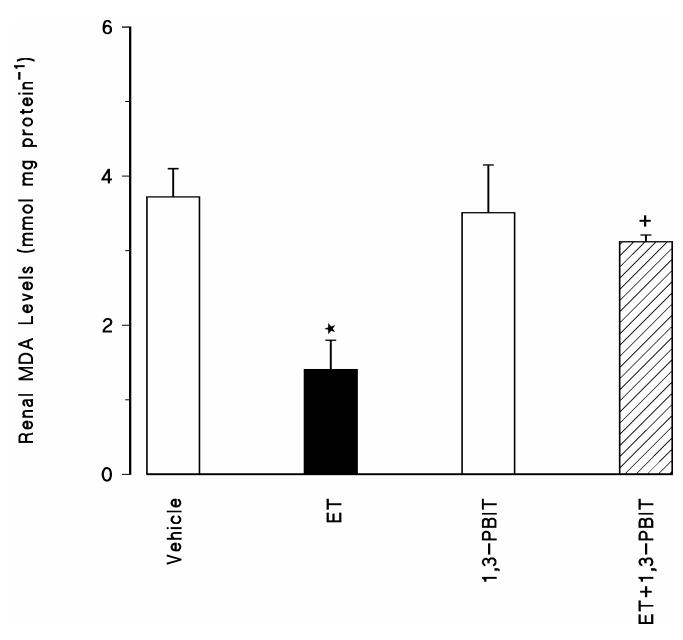

Fig. 3: Effect of iNOS inhibition by 1,3-PBIT on changes in renal malondialdehyde (MDA) levels $4 \mathrm{hr}$ after saline or endotoxin (ET) injection in conscious rats. Values are expressed as means \pm SEM from 5-7 rats per treatment group. ${ }^{*} P<0.05$ vs. saline-treated group (vehicle). ${ }^{+} P<0.05$ vs. ET-treated group.

It is well known that oxidative stress results from an oxidant/antioxidant imbalance, an excess of oxidants and/or a depletion of antioxidants ${ }^{[4]}$. However, there are conflicting reports showing the effect of NO on lipid peroxidation $^{[21,23]}$ and oxidative stress ${ }^{[1,3,4]}$.
Although increased activity of antioxidant enzymes such as xanthine oxidase, superoxide dismutase and glutathione peroxidase has been reported in patients with sepsis, MDA levels have also shown to be increased, suggesting that the elevations of these antioxidant enzymes are not so effective as to prevent cellular damage ${ }^{[5]}$. In the present study, endotoxininduced increase in the nitrite levels in serum and kidney was associated with increased renal MDA levels which were prevented by 1,3-PBIT. Therefore, it can be concluded that NO produced by iNOS mediates the endotoxin-induced increase in total antioxidant capacity and consequently decrease in lipid peroxidation. These results are also consistent with the observation that NO behaves as a potent antioxidant ${ }^{[21]}$.

There are contradictory reports in the literature concerning role of $\mathrm{NO}$ as an antiinflammatory or proinflammatory agent ${ }^{[7,17,18]}$. In the present study, we found that endotoxin-induced increase in the levels of nitrite in serum and kidney which were prevented by 1,3-PBIT was associated with decreased MPO activity. However, decreased renal MPO activity was not reversed by $1,3-\mathrm{PBIT}$. These results suggest that NO produced by iNOS, expressed in, at least, kidney, does not act as an proinflammatory mediator in this endotoxemia model in rat.

In summary, overproduction of NO during endotoxemia leads to suppression of lipid peroxidation in renal tissue. Selective inhibition of iNOS with 1,3PBIT restores renal antioxidant capacity presumably due to decreased levels of antioxidant molecules or activities of antioxidant enzyme systems. Impairment of renal function is critically involved in the pathophysiological sequale in septic shock finally resulting in multiorgan failure and death; restoration of these impaired functions should improve therapeutic benefit. Our results suggest that treatment with the selective iNOS could improve the renal function and increased antioxidant capacity in patients during septic shock.

\section{ACKNOWLEDGEMENTS}

This work was supported by the Research Foundation of Mersin University (Project Code No: BAP ECZ F EMB (KB) 2003-1). A part of this work has been presented at $18^{\text {th }}$ National Congress of Pharmacology, İzmir, Turkey, September 28-October 1, 2005.

\section{REFERENCES}

1. Victor, V.M., M. Rocha and M. De la Fuente, 2004. Immune cells: Free radicals and antioxidant in sepsis. Int. Immunopharmacol., 4: 327-347.

2. Cadenas, S. and A.M. Cadenas, 2002. Fighting the stranger-antioxidant protection against endotoxin toxicity. Toxicology, 18: 45-63. 
3. Cuzzocrea, S., D.P. Riley, A.P. Caputi and D. Salvemini, 2001. Antioxidant therapy: A new pharmacological approach in shock, inflammation and ischemia/reperfusion injury. Pharmacol. Rev., 53: 135-159.

4. Salvemini, D. and S. Cuzzocrea, 2002. Oxidative stress in septic shock and disseminated intravascular coagulation. Free Radic. Biol. Med., 33: 1173-1185.

5. Pascual, C., W. Karzai, A. Meier-Hellmann, M. Oberhoffer, A. Horn, D. Bredle and K. Reinhart, 1998. Total plasma antioxidant capacity is not always decreased in sepsis. Crit. Care Med., 26: 705-709.

6. Batra, S., R. Kumar, R. Seema, A.K. Kapoor and G. Ray, 2000. Alterations in antioxidant status during neonatal sepsis. Ann. Trop. Paediatr., 20: 27-33.

7. Tunctan, B. and S. Altug, 2004. The use of nitric oxide synthase inhibitors in inflammatory diseases: A novel class of anti-inflammatory agents. Curr. Med. Chem.: Anti-Inflammatory \& Anti-Allergy Agents, 3: 271-301.

8. Tunctan, B., F.A. Yaghini, A. Estes and K.U. Malik, 2005. Inhibition by nitric oxide of cytochrome P450 4A activity contributes to endotoxin-1nduced hypotension in rats. Nitric Oxide: Biol. Chem., 14: 51-57.

9. Bradford, M.M., 1976. A rapid and sensitive method for the quantitation of microgram quantities of protein utilizing the principle of protein-dye binding. Anal. Biochem., 72: 248-254.

10. Butler, A.R., F.W. Flitney and D.L.H. Williams, 1995. NO, nitrosonium ions, nitroxide ions and iron-nitrosyls in Biology: A chemists perspective. Trends Pharmacol. Sci., 16: 18-22.

11. Ignarro, L.J., J.M. Fukuto, J.M. Griscavage, N.E. Rogers and R.E. Byrns, 1993. Oxidation of nitric oxide in aqueous solution to nitrite but not nitrate: comparison with enzymatically formed nitric oxide from L-Arginine. Proc. Natl. Acad. Sci. U.S.A., 90: 8103-8107.

12. Tunctan, B., O. Uludag, S. Altug and N. Abacioglu, 1998. Effects of nitric oxide synthase inhibition in lipopolysaccharide-induced sepsis in mice. Pharmacol. Res., 38: 405-411.

13. Tunctan, B., O. Uludag, S. Altug and N. Abacioglu, 2000. Time-dependent variations in serum nitrite, 6-keto-prostaglandin $\mathrm{F}_{1 \alpha}$ and thromboxane $\mathrm{B}_{2}$ levels induced by lipopolysaccharide in mice. Biol. Rhythm Res., 31: 499-514.
14. Tunctan, B., O. Uludag, S. Altug, B. Demirkay and N. Abacioglu, 2003. Effects of cyclooxygenase inhibitors on nitric oxide production and survival in a mice model of sepsis. Pharmacol. Res., 48: $37-48$.

15. Chance, B. and A.C. Maehley, 1955. Assay of Catalases and Peroxidases. In: Methods in Enzymology (Eds. S. Colowick and N. Kaplan) pp: 764-775. Academic Press, New York.

16. Yagi, K., 1994. Lipid Peroxides and Related Radicals in Clinical Medicine. In: Free Radicals in Diagnostic Medicine (Ed. D. Armstrong) pp: 1-15. Plenum Press, New York.

17. Cuzzocrea, C., 2004. Effect of inhibitors of nitric oxide in animal models and future directions for therapy in inflammatory disorders. Curr. Med. Chem. Anti-Inflammatory \& Anti-Allergy Agents, 3: 261-270.

18. Blantz, R.C. and K. Munger, 2002. Role of nitric oxide in inflammatory conditions. Nephron, 90: 373-378.

19. Wu, C.C., 2004. Nitric oxide and inflammation. Curr. Med. Chem.: Anti-Inflammatory \& AntiAllergy Agents, 3: 217-222.

20. Tunctan, B., F.A. Yaghini, A. Estes and K.U. Malik, 2004. Prostaglandins inhibit cytochrome P450 4A activity and contribute to endotoxininduced hypotension in rats via nitric oxide production. FASEB, Suppl 18: A1037-A1038.

21. Bloodsworth, A., V.B. O'Donnell and B.A. Freeman, 2000. Nitric oxide regulation of free radical- and enzyme-mediated lipid and lipoprotein oxidation. Arterioscler. Thromb. Vasc. Biol., 20: 1707-1715.

22. d'Ischia, M., A. Palumbo and F. Buzzo, 2000. Interactions of nitric oxide with lipid peroxidation products under aerobic conditions: Inhibitory effects on the formation of malondialdehyde and related thiobarbituric acid-reactive substances. Nitric Oxide: Biol. Chem., 4: 4-14.

23. Hogg, N. and B. Kalyanaraman, 1999. Nitric oxide and lipid peroxidation. Biochim. Biophys. Acta., 1411: 378-384. 